\title{
Comparative study of intra-vaginal misoprostol with intra-cervical dinoprostone gel for induction of labour
}

\begin{abstract}
Objective of the study: To compare the safety and efficacy of intra-vaginal Misoprostol with intra-cervical Dinoprostone gel for induction of labour.

Materials and methods: 150 Patients who required labour induction were included in this prospective cross sectional study from October 2014 to June 2016. 75 of them received $0.5 \mathrm{mg}$ intra-cervical Dinoprostone gel (PGE2) and 75 patients received $50 \mathrm{mcg}$ of intravaginal Misoprostol tablet and dose was repeated every 6 hours for up to maximum of 3 doses. Factors such as parity, GA, induction to delivery time, indication for induction, No. of doses required, need of Oxytocin, MBS prior to induction, mode of delivery, indication for C- section, side effects, No. of NICU admissions and indication, MSL were studied in detail.

Results: The majority of patients had gestational age above 40 weeks and between $37-40$ weeks in PGE2 and Misoprostol group respectively. The mean induction to delivery time was $10.29 \pm 7.19$ hours and $7.64 \pm 5.75$ hours with PGE2 and Misoprostol respectively. $52 \%$ in PGE2 group had indication for induction as postdated pregnancy and $29.3 \%$ in Misoprostol group had SPE as indication which formed majority of cases. $10.7 \%$ and $37.3 \%$ in PGE2 group and Misoprostol group had side effects respectively. All these factors were statistically significant. C- section rate in both the groups was $32 \%$.

Conclusion: Both Misoprostol and PGE2 are safe and effective drugs for cervical ripening and labour induction but Misoprostol is more cost effective and stable at room temperature and induction to delivery time was significantly less with it but more side effects were seen. No. of doses required were less with PGE2. Failure of induction was more with PGE2 and fetal distress was more with Misoprostol. These findings suggest that Misoprostol is safe, effective and less expensive drug for cervical ripening and induction of labour.
\end{abstract}

Volume 6 Issue 5 - 2017

\author{
Ramya D, Jaju PB \\ Department of Obstetrics and Gynaecology, BLDE University, \\ India
}

Correspondence: Ramya D, BLDE University, Room No: A-6, NRI hostel, BLDE campus, Vijayapura, Karnataka, India, Tel 8867457378,Email ramyareddy.depa3@gmail.com

Received: February 09, 2017 | Published: April 20, 2017

Keywords: Dinoprostone, Misoprostol, Induction of labour, Modified Bishop score, vaginal delivery, $\mathrm{C}$ - section

Abbreviations: NICU, Neonatal Intensive Care Unit; MBS, Modified Bishop Score; Mcg, Micrograms; MSL, Meconium Stained Liquor; GA, Gestational Age; SPE, Severe Preeclampsia

\section{Introduction}

Labour is a final consequence of Pregnancy and is inevitable. The timing of onset of labour may vary widely, but it will happen sooner or later. Induction of labour implies the artificial initiation of uterine contractions after period of viability for the purpose of vaginal delivery where as augmentation of labour is a process of stimulation of uterine contractions that are already present but found to be inadequate. ${ }^{1}$ Induction of labour is indicated when continuation of pregnancy risks the life of mother or fetus. The baby should be delivered in a good condition, in an acceptable time frame and with minimum maternal discomfort and least side effects.

In order to be successful, induction of labour must lead to adequate uterine contractions which increases in frequency, duration and progressive dilatation of cervix. It should result in vaginal delivery, as there is little purpose in bringing about labour as a mere preparation for caesarean section. ${ }^{1}$ The aim is to achieve vaginal delivery with minimal risk to mother and fetus. Induction of labour is common procedure of obstetric practice. ${ }^{2}$ It is indicated in $10 \%-15 \%$. $^{2}$ of pregnant women.

The cervix is an organ of diverse properties. Ripening of the cervix takes place before the onset of labour resulting in increased softening, effacement. Pharmacologically and physiologically prostaglandins have two direct actions associated with labour. They are ripening of the cervix and myometrial contractility.

The method of administration that has been well known is endocervical Dinoprostone or prostaglandin E2. Though this is widely used, the disadvantage is that it is expensive and required refrigeration for storage with warming before use. Later, a comparably cheap, safe and effective vaginally administered Prostaglandin, which claims to have limited side effects available with the name Misoprostol or PGE1 in tablet form. It does not need any refrigeration. A number of recently published clinical trials abroad and in India have shown that intravaginal Misoprostol is an effective agent for induction of labour and cervical ripening at term, when compared to other methods of labour induction.

In this study, intracervical dinoprostone (PGE2) gel is compared to intravaginal misoprostol in the induction of labour and its efficacy and safety for the mother and fetus.

\section{Material and methods}

\section{Source of Data}

A. 150 Patients admitted to labour ward of OBG Dept of SHRI B M Patil medical College and Research Hospital with an indication for induction of labour from October 2014 to June 2016.

B. It is a prospective cross- sectional comparative study. 


\section{Indications for induction in our study}

a. Mild pre eclampsia.

b. Severe pre eclampsia.

c. Post dated pregnancy.

d. Mild polyhydramnios.

e. Mild oligohydramnios.

f. Gestational Diabetes Mellitus.

g. Chronic hypertension.

h. Mild IUGR.

i. Chorioamnionitis.

\section{Inclusion criteria}

i. Indication for labour induction

ii. Singleton pregnancy.

iii. Gestational age more than 28 weeks.

iv. Vertex presentation.

v. Bishop score $\leq 5$.

\section{Exclusion criteria}

a. Previous L.S.C.S or any uterine surgery.

b. Mal presentation.

c. Contracted pelvis or cephalopelvic disproportion.

d. Antepartum haemorrhage.

e. Unsatisfactory CTG.

f. Severe IUGR.

g. Active genital herpes.

h. Pelvic tumors.

i. Bronchial asthma.

\section{Method of induction}

i. After informed consent had been obtained, the patients selected for the study were evaluated initially by modified Bishop's score and admission test for fetal well being. Patients with a modified bishops score $\leq 5$ and a positive admission test were induced.

ii. 75 patient with an indication for labour induction received with $50 \mu \mathrm{g}$ of intravaginal misoprostol and repeated for a maximum of 3 doses every 6 hours as needed.

iii. 75 patients with an indication for induction of labour received $0.5 \mathrm{mg}$ intracervical dinoprostonegel and repeated for a maximum of 3 doses every 6 hours as needed.

iv. After drug insertion, patients were monitored for signs of labour, maternal vital signs, fetal heart rate and progress of labour. The fetal heart rate was monitored by either intermittent auscultation or continuous fetal heart rate monitoring. A partogram was strictly maintained in all patients.

v. Oxytocin was started depending on the modified Bishop's score and in the absence of adequate uterine contractions after $6 \mathrm{hrs}$ of the last dose, or for augmentation of labour in case of an arrest of dilation. Oxytocin was started at the dose of 5 units in 5ooml RL in Primigravida and 2.5 units in 500ml RL in multigravida and titrated accordingly.

vi. Membranes were ruptured, when the cervix was completely effaced with a cervical dilatation of more than $3 \mathrm{cms}$ or at onset of active stage of labour.

vii. The data collection included induction, for indication, maternal age, parity, gestational age on entry into the study, modified Bishop's Score at time induction, induction - delivery interval, oxytocin augmentation, type of delivery, Apgar score of the baby, maternal and neonatal complications.

viii. The results observed were subjected to statistical analysis by students ' $t$ ' test, odds ratio, chi-square test and a 'p' value of $<$ 0.05 was considered as significant.

\section{Definitions and criteria}

A. Induction was considered 'failed induction' if contractions did not start or if bishop score did not increase at end of 24 hours.

B. Tachysystole was defined as more than 5 uterine contractions per 10 minutes without fetal heart rate (FHR) changes, for 2 consecutive 10 minute periods.

C. Hyperstimulation was defined as exaggerated uterine response accompanied by fetal heart rate decelerations or tachycardia.

\section{Observations and results}

Total number of patients studied was 150.75 patients were induced with $50 \mu \mathrm{gms}$ intravaginal Misoprostol tablet and repeated every $6^{\text {th }}$ hourly up to 3 doses. And the other 75 patients were induced with $0.5 \mathrm{mg}$ intracervical Dinoprostone gel and repeated every $6^{\text {th }}$ hourly up to 3 doses.

\section{Statistical analysis}

All characteristics were summarized descriptively. For continuous variables, the summary statistics of $\mathrm{N}$, mean, standard deviation (SD) were used. For categorical data, the number and percentage were used in the data summaries. Chi-square $\left(\chi^{2}\right)$ /Fisher exact test was employed to determine the significance of differences between groups for categorical data. The difference of the means of analysis variables was tested with the unpaired t-test. If the p-value was $<0.05$, then the results will be considered to be significant. Data were analyzed using SPSS software v.23.0.

The following observations were made

a. Parity was compared in both groups and found to be almost similar, with no statistical significance $(\mathrm{P}=0.507)$. Primigravida formed the largest group in the study being $56 \%$ and $61.3 \%$ in dinoprostone and misoprostol group respectively. Multigravida in dinoprostone and misoprostol groups were $44 \%$ and $38.7 \%$ respectively (Table 1).

b. From the Table 2 when gestational age was compared it was seen that there was more number of patients between 37 to 40 weeks $(61.3 \%)$ in misoprostol group and more number of patients with gestational age more than 40 weeks $(56.0 \%)$ in Dinoprostone group. This was statistically significant $(\mathrm{P}<0.002)$.

c. The mean induction delivery interval in dinoprostone is $10.29 \pm$ 7.19 hours. The mean induction delivery interval in misoprostol was $7.64 \pm 5.75$ hours. Mean induction delivery interval is shorter in Misoprostol group and is statistically significant (Table 3). 
d. The largest group for induction in Dinoprostone group was Post dated pregnancy $(52.0 \%)$ and in Misoprostol group was severe preeclampsia $(29.3 \%)$. There was statistical significance as the $p$ value is 0.001 (Table 4).

e. The Table 5 represents the distribution of cases according to total number of doses required. In Dinoprostone group maximum number doses required was 2 and where as in Misoprostol group it is 3 . The difference is statistically significant $(\mathrm{p}$ value $=0.025)$.

f. Need for oxytocin augmentation was almost equal in both the groups and statistically not significant. Need for oxytocin was $10.7 \%$ and $9.3 \%$ in Dinoprostone and Misoprostol group respectively (Table 6).

g. The $\mathrm{p}$ value related to Modified bishop score in both the dinoprostone and Misoprostol group is 0.034 and is statistically significant. $77.3 \%$ and $22.7 \%$ of patients had MBS of 3 and 4 respectively in Dinoprostone group. In Misoprostol group, 61.3\% and $38.7 \%$ of patients had MBS as 3 and 4 respectively (Table 7).

h. The mode of delivery in both the groups was same. $32.0 \%$ and $68.0 \%$ of patients in both the Dinoprostone group and Misoprostol group underwent $\mathrm{C}$ - Section and vaginal delivery respectively (Table 8) i. The Table 9 indicates the indications for $\mathrm{C}$ - section in the present study. In both the groups, $\mathrm{C}$ - section rate was same and doesn't have any statistical significance. But when analyzed, Dinoprostone group has higher rate of indications failure and where as Misoprostol group has higher rate of fetal distress which where indictions for $\mathrm{C}$ - section.

j. The Table 10 represents the side effects in both the Dinoprostone and Misoprostol groups. With this data it is evident that there is higher incidence of side effects in Misoprostol group and is statistically significant ( $\mathrm{p}$ value $=0.003$ ). The major side effect in the Misoprostol group was chills.

$\mathrm{k}$. The Table 11 shows the mean number of days the babies were admitted in NICU. One baby from misoprostol group was taken against medical advice (AMA) which was represented as +1 . NICU admissions were double in the dinoprostone group when compared to misoprostol group. There is no statistical significance in NICU admissions in both the groups.

1. The Table 12 represents the indication for NICU admissions in both Dinoprostone group and Misoprostol group. There is no statistical difference between both the groups.

Table I Distribution of cases by Parity between study groups

\begin{tabular}{lllll}
\hline \multirow{2}{*}{ Parity } & \multicolumn{2}{l}{ Dinoprostone } & \multicolumn{2}{c}{ Misoprostol } \\
& N & $\%$ & N & $\%$ \\
\hline Multi & 33 & $44.0 \%$ & 29 & $38.7 \%$ \\
Primi & 42 & $56.0 \%$ & 46 & $61.3 \%$ \\
Total & 75 & $100.0 \%$ & 75 & $100.0 \%$ \\
\hline
\end{tabular}

Table 2 Distribution of cases by Gestation Age between study groups

\begin{tabular}{|c|c|c|c|c|c|}
\hline \multirow{2}{*}{ Gestation Age } & \multicolumn{2}{|c|}{ Dinoprostone } & \multicolumn{2}{|c|}{ Misoprostol } & \multirow{2}{*}{ p value } \\
\hline & $\mathbf{N}$ & $\%$ & $\mathbf{N}$ & $\%$ & \\
\hline$<37$ weeks & 8 & $10.7 \%$ & 7 & $9.3 \%$ & \multirow{4}{*}{0.002 (Sig) } \\
\hline $37-40$ weeks & 25 & $33.3 \%$ & 46 & $61.3 \%$ & \\
\hline$>40$ weeks & 42 & $56.0 \%$ & 22 & $29.3 \%$ & \\
\hline Total & 75 & $100.0 \%$ & 75 & $100.0 \%$ & \\
\hline
\end{tabular}

Table 3 Mean Induction Delivery Interval between study groups

\begin{tabular}{llll}
\hline Mean induction delivery interval & Dinoprostone & Misoprostol & p value \\
\hline Mean \pm SD & $10.29 \pm 7.19$ & $7.64 \pm 5.75$ & $0.014(\mathrm{Sig})$
\end{tabular}

Table 4 Distribution of cases by Indications for Induction between study groups

\begin{tabular}{|c|c|c|c|c|c|}
\hline \multirow{2}{*}{ Indications for induction } & \multicolumn{2}{|c|}{ Dinoprostone } & \multicolumn{2}{|c|}{ Misoprostol } & \multirow{2}{*}{ p value } \\
\hline & $\mathbf{N}$ & $\%$ & $\mathbf{N}$ & $\%$ & \\
\hline APE & 2 & $2.7 \%$ & 0 & $0.0 \%$ & \\
\hline GHTN & 16 & $21.3 \%$ & 14 & $18.7 \%$ & \\
\hline IE & 2 & $2.7 \%$ & 2 & $2.7 \%$ & \\
\hline MPE & 5 & $6.7 \%$ & 18 & $24.0 \%$ & $0.00 \mathrm{I}$ (Sig) \\
\hline PD & 39 & $52.0 \%$ & 19 & $25.3 \%$ & \\
\hline SPE & II & $14.7 \%$ & 22 & $29.3 \%$ & \\
\hline Total & 75 & $100.0 \%$ & 75 & $100.0 \%$ & \\
\hline
\end{tabular}

Table 5 Distribution of cases by No. of doses required

\begin{tabular}{llllll}
\hline No. of Doses required & dinoprostone & & Misoprostol & p value \\
\hline Dose I & $\mathbf{N}$ & $\%$ & $\mathbf{N}$ & $36.0 \%$ & \\
Dose 2 & 42 & $56.0 \%$ & 27 & $56.0 \%$ & $0.025(\mathrm{Sig})$ \\
Dose 3 & 33 & $44.0 \%$ & 62 & $8.0 \%$ \\
Total & 0 & $0.0 \%$ & 75 & $100.0 \%$ \\
\hline
\end{tabular}


Table 6 Distribution of cases by Need of Oxytocin between study groups

\begin{tabular}{llllll}
\hline \multirow{2}{*}{ Need of oxytocin } & \multicolumn{2}{c}{ Dinoprostone } & \multicolumn{2}{c}{ Misoprostol } & \multicolumn{2}{c}{ P value } \\
\hline Yes & $\mathbf{N}$ & $\%$ & $\mathbf{N}$ & $\%$ & \multirow{2}{*}{0.785} \\
No & 8 & $10.7 \%$ & 7 & $9.3 \%$ & \\
Total & 67 & $89.3 \%$ & 68 & $90.7 \%$ & 75 \\
\hline
\end{tabular}

Table 7 Distribution of cases by Modified Bishop's Score between study groups

\begin{tabular}{llllll}
\hline \multirow{2}{*}{ Modified bishop's score } & \multicolumn{2}{l}{ Dinoprostone } & \multicolumn{2}{l}{ Misoprostol } & \multirow{2}{*}{ p value } \\
\hline 3 & $\mathbf{N}$ & $\%$ & $\mathbf{N}$ & $\%$ & \\
4 & 58 & $77.3 \%$ & 46 & $61.3 \%$ & $0.034(\mathrm{Sig})$ \\
Total & 17 & $22.7 \%$ & 29 & $38.7 \%$ & \\
\hline
\end{tabular}

Table 8 Distribution of cases by Mode of Delivery between study group

\begin{tabular}{llllll}
\hline \multirow{2}{*}{ Mode of delivery } & Dinoprostone & \multicolumn{2}{c}{ Misoprostol } & \multicolumn{2}{c}{ P value } \\
\hline CS & $\mathbf{N}$ & $\%$ & $\mathbf{N}$ & $\%$ & \\
VD & 24 & $32.0 \%$ & 24 & $32.0 \%$ & NA \\
Total & 51 & $68.0 \%$ & 51 & $68.0 \%$ & \\
\hline
\end{tabular}

Table 9 Distribution of cases by Indication for C- section between study groups

\begin{tabular}{llllll}
\hline Indication for & dinoprostone & \multicolumn{2}{c}{ Misoprostol } & \multirow{2}{*}{ P value } \\
C- section & $\mathbf{N}$ & $\%$ & $\mathbf{N}$ & $\%$ & \\
\hline Fetal Distress & 12 & $16.0 \%$ & 18 & $24.0 \%$ & 0.299 \\
Failure of Induction & II & $14.7 \%$ & 6 & $8.0 \%$ & \\
NPOL & $\mathrm{I}$ & $1.3 \%$ & 0 & $0.0 \%$ & $32.0 \%$ \\
Total & 24 & $32.0 \%$ & 24 & 3 & \\
\hline
\end{tabular}

Table 10 Clinical and biochemical variables of individuals with overweight-obesity

\begin{tabular}{|c|c|c|c|c|c|}
\hline \multirow{2}{*}{ Side effects } & \multicolumn{2}{|c|}{ Dinoprostone } & \multicolumn{2}{|c|}{ Misoprostol } & \multirow{2}{*}{$p$ value } \\
\hline & $\mathbf{N}$ & $\%$ & $\mathbf{N}$ & $\%$ & \\
\hline$\overline{\mathrm{APH}}$ & 2 & $2.7 \%$ & I & $1.3 \%$ & \\
\hline Diarrhoea & 0 & $0.0 \%$ & 1 & $1.3 \%$ & \\
\hline Fever & 1 & $1.3 \%$ & 2 & $2.7 \%$ & \\
\hline HS & 2 & $2.7 \%$ & 6 & $8.0 \%$ & \\
\hline TPH & 1 & $1.3 \%$ & 1 & $1.3 \%$ & 0.003 (Sig) \\
\hline TS & 0 & $0.0 \%$ & 2 & $2.7 \%$ & \\
\hline Vomiting & 2 & $2.7 \%$ & 2 & $2.7 \%$ & \\
\hline Chills & 0 & $0.0 \%$ & 13 & $17.3 \%$ & \\
\hline Total & 8 & $10.7 \%$ & 28 & $37.3 \%$ & \\
\hline
\end{tabular}

Table I I Distribution of cases by ICU admissions (days) between study groups

\begin{tabular}{|c|c|c|c|c|c|}
\hline \multirow{2}{*}{$\begin{array}{l}\text { ICU Admissions } \\
\text { (Days) }\end{array}$} & \multicolumn{2}{|c|}{ Dinoprostone } & \multicolumn{2}{|c|}{ Misoprostol } & \multirow{2}{*}{ P Value } \\
\hline & $\mathbf{N}$ & $\%$ & $\mathbf{N}$ & $\%$ & \\
\hline$\leq 7$ & 5 & $6.7 \%$ & I & $1.3 \%$ & \\
\hline$>7$ & 3 & $4.0 \%$ & 3 & $4.0 \%$ & 0.221 \\
\hline Total & 8 & $10.7 \%$ & $4+1$ & $6.7 \%$ & \\
\hline
\end{tabular}

Table 12 Distribution of cases by Indication for NICU Admission between study groups

\begin{tabular}{llllll}
\hline \multirow{2}{*}{ Indication for NICU admission } & Dinoprostone & \multicolumn{3}{c}{ Misoprostol } & P Value \\
\cline { 2 - 3 } & $\mathbf{N}$ & $\%$ & $\mathbf{N}$ & $\%$ & \\
\hline Birth asphyxia & 0 & $0.0 \%$ & $\mathrm{I}$ & $1.3 \%$ \\
LBW & 2 & $2.7 \%$ & 2 & $2.7 \%$ & \\
VLBW & $\mathrm{I}$ & $1.3 \%$ & 2 & $2.7 \%$ & 0.38 \\
MAS & 2 & $2.7 \%$ & 0 & $0.0 \%$ & \\
PTC & 2 & $2.7 \%$ & 0 & $0.0 \%$ & \\
RDS & 1 & $1.3 \%$ & 0 & $0.0 \%$ \\
Total & 8 & $10.7 \%$ & 5 & $6.7 \%$ & \\
\hline
\end{tabular}




\section{Discussion}

In the present study 150 patients were studied with indications for induction of labour of which 75 patients received intracervical Dinoprostone gel containing $0.5 \mathrm{mg}$ and 75 patients received

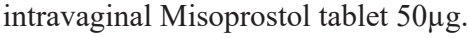

\section{Patients' characteristics}

Parity: There is no statistical significance regarding parity in both the groups.

Gestational age: Majority of patients are of above 40 weeks of gestational age in Dinoprostone group where as in Misoprostol group, majority of cases are in between 37 to 40 weeks of gestational age. It is statistically significant $(\mathrm{p}=0.002)$.

Table 13 Dinoprostone Vaginal Delivery Rate

\section{Indication for induction}

Dinoprostone group has high number of cases with indication as post dated pregnancy while Misoprostol group has high number of cases with indication as severe preeclampsia. And it is statistically significant $(\mathrm{p}=0.001)$

\section{Response to drug}

\section{Vaginal deliveries}

The rate of vaginal deliveries was $68 \%$ in both Dinoprostone group and in the Misoprostol group (Table 13). In present study, the rate of vaginal delivery in the Dinoprostone group is consistent with the studies of Bernstein et al. ${ }^{6}$ The vaginal delivery rate with Misoprostol group in present study is comparable to the studies of Herabutya et al. ${ }^{9}$ in which vaginal delivery rate was $69 \%$ (Table 14 ).

\begin{tabular}{ll}
\hline $\begin{array}{l}\text { Dinoprostone } \\
\text { authors and year }\end{array}$ & Vaginal delivery rate \\
\hline Trufatter et al. $^{3}$ & $73.30 \%$ \\
Yonekura et al. $^{4}$ & $60.00 \%$ \\
Nager et al. ${ }^{5}$ & $73.70 \%$ \\
Bernstein et al. & $69.20 \%$ \\
Present Study & $68.00 \%$ \\
\hline
\end{tabular}

Table I 4 Misoprostol Vaginal Delivery Rate

\begin{tabular}{ll} 
Misoprostol & \\
authors and year & Vaginal delivery rate \\
\hline Fletcher et al. $^{7}$ & $91.70 \%$ \\
Bugalho et al. $^{8}$ & $92.20 \%$ \\
Herabutya et al. ${ }^{\circ}$ & $69.00 \%$ \\
Present Study & $68.00 \%$
\end{tabular}

\section{Bishop's score}

In the present study there is statistical difference in regard to Bishop score prior to induction in both the groups $(p=0.034)$ Majority of cases had 3 as their Bishop score. When both the groups are compared, Dinoprostone group had more number of cases with Bishop score 3 and more number of cases in Misoprostol group had Bishop score 4.

\section{Induction to vaginal delivery interval}

In the present study it was seen that the induction delivery interval was shorter in the Misoprostol group compared to Dinoprostone group, $10.89 \pm 7.28 \mathrm{hrs}$ and $7.83 \pm 5.63 \mathrm{hrs}$ respectively. This was statistically significant $(\mathrm{P}<0.05)$. In the present study the induction - delivery interval of Dinoprostone is comparable to the studies of Nager et al. ${ }^{5}$ and Bernstein et al. ${ }^{6}$ (Table 15).

In the Misoprostol group it has been shown that by various dosages of Misoprostol used the induction - delivery interval also varies. Our present study uses 50 $\mu$ g Misoprostol every 6th hourly with an induction delivery interval of $7.83 \pm 5.63 \mathrm{hrs}$ which is comparable to the studies of Bugalho et al. ${ }^{8}$ who has used $50 \mu \mathrm{g}$ Misoprostol $12^{\text {th }}$ hourly to a maximum of $200 \mu \mathrm{g}$ with an induction delivery interval of $10.4 \mathrm{hrs}$ and Sanchez Ramos et al. ${ }^{10}$ who used $50 \mu \mathrm{g}$ Misoprostol $4^{\text {th }}$ hourly to a maximum of $600 \mu \mathrm{g}$ with an induction delivery interval of $11 \pm 7.3 \mathrm{hrs}$ (Table 16).

Table 15 Induction to vaginal delivery interval

\begin{tabular}{ll}
\hline Authors and year & Induction delivery interval in hours \\
\hline Trufatter et al. ${ }^{3}$ & $13.3 \pm 6.2$ \\
Yonekura et al. & $13.1 \pm 8.1$ \\
Nager et al. ${ }^{5}$ & $10.1 \pm 2.1$ \\
Bernstein et al. & $12.3 \pm 16.5$ \\
Present Study & $10.89 \pm 7.28$ \\
\hline
\end{tabular}

Table 16 Induction to vaginal delivery interval

\begin{tabular}{lll}
\hline $\begin{array}{l}\text { Misoprostol } \\
\text { authors and year }\end{array}$ & Dosage max dose & IDI (hrs) \\
\hline Sanchez Ramos et al. ${ }^{10}$ & $50 \mu \mathrm{g} 4 \mathrm{hrs}(600 \mu \mathrm{g})$ & $1 \mathrm{II} 7.3$ \\
Fletcher et al. $^{7}$ & $100 \mu \mathrm{g}(100 \mu \mathrm{g})$ & $15.6 \pm 12.5$ \\
Wing et al." & $50 \mu \mathrm{g} 3 \mathrm{hrs}(300 \mu \mathrm{g})$ & $15.1 \pm 8$ \\
Wing et al. & $25 \mu \mathrm{g} 3 \mathrm{hrs}(200 \mu \mathrm{g})$ & $22.1 \pm 14.5$ \\
Bugalho et al. & $50 \mu \mathrm{g} \mathrm{I} 2 \mathrm{hrs}(200 \mu \mathrm{gg})$ & 10.4 \\
Present Study & $50 \mu \mathrm{g} 6 \mathrm{hr}(150 \mu \mathrm{g})$ & $7.83 \pm 5.63$ \\
\hline
\end{tabular}


Various authors in their studies have compared the efficacy of Misoprostol and Dinoprostone in relation to induction - delivery interval. In the present study the outcome of induction delivery interval is much shorter than the various studies and almost comparable to the studies of Ozgur et al. ${ }^{14}$

\section{Failed induction}

Failed inductions were those cases in which contractions did not start or bishop did not improve at the end of 24 hours and were taken up for caesarean section with failure of induction as an indication.

Caesarean delivery rates in the present study are $32 \%$ in both the
Dinoprostone group and the Misoprostol group. The other indications were fetal distress, non- progression of labour. In the Dinoprostone group, failure of induction formed the major indication for caesarean delivery and in the Misoprostol group fetal distress formed the major indication for caesarean delivery. In the Misoprostol group it was seen that two cases which had fetal distress, preoperatively it was found to have thick meconium stained liquor (Table 18). In our study the caesarean section rate with Dinoprostone was $32 \%$, which is consistent with the studies of Bernstein et al. ${ }^{6}$ In Misoprostol group the caesarean section rate was $32 \%$ which is consistant with the studies of Herabutya et al. ${ }^{9}$ (Table 19).

Table 17 Induction to vaginal delivery interval

\begin{tabular}{lll}
\hline Authors and year & $\begin{array}{l}\text { Dinoprostone } \\
\text { (Dosage) }\end{array}$ & $\begin{array}{l}\text { Misoprostol } \\
\text { (Dosage) }\end{array}$ \\
\hline Varaklis et al. ${ }^{13}$ & $22.4 \pm 10.9(0.5 \mathrm{mg} 6 \mathrm{hrs})$ & $16.0 \pm 7.7(25 \mu \mathrm{g} 2 \mathrm{hrs})$ \\
Wing Da et al." & $23.5 \pm 14.5(0.5 \mathrm{mg} 6 \mathrm{hrs})$ & $15.1 \pm 8.0(50 \mu \mathrm{g} \mathrm{hrs})$ \\
Herabutya et al. & $21.36 \pm 13.09(1.5 \mathrm{mg})$ & $19.14 \pm 10.6(100 \mu \mathrm{\mu g})$ \\
Ozgur et al..$^{14}$ & $8.2 \pm 5.9(0.5 \mathrm{mg})$ & $7.6 \pm 1.9(100 \mu \mathrm{g})$ \\
Blanchette et al. ${ }^{15}$ & $31.3 \pm 13.0$ & $19.8 \pm 10.4$ \\
Kolderup et al. & $28.52(0.5 \mathrm{mg} 6 \mathrm{hrs})$ & $19.5(50 \mu \mathrm{g} 4 \mathrm{hrs})$ \\
Present Study & $10.89 \pm 7.28(0.5 \mathrm{mg} 6 \mathrm{hrs})$ & $7.83 \pm 5.63(50 \mu \mathrm{g} 6 \mathrm{hrs})$ \\
\hline
\end{tabular}

Table 18 Caesarean Section Rate in Dinoprostone group

\begin{tabular}{ll}
\hline $\begin{array}{l}\text { Dinoprostone } \\
\text { author and year }\end{array}$ & C.S. Rate \\
\hline Trufatter et al. $^{3}$ & $26.70 \%$ \\
Yonekura et al. $^{4}$ & $40 \%$ \\
Nager et al. ${ }^{5}$ & $26.30 \%$ \\
Bernstein et al. & \\
Present Study & $30.80 \%$ \\
\hline
\end{tabular}

Table 19 Caesarean Section Rate in Misoprostol group

\begin{tabular}{ll}
\hline Misoprostol & \\
author and year & C.S. Rate \\
\hline Wing DA et al." & $14.70 \%$ \\
Blanchette et al. $^{15}$ & $25.60 \%$ \\
Fletcher et al. $^{7}$ & $3.12 \%$ \\
Herabutya et al. & $31 \%$ \\
Present Study & $32 \%$
\end{tabular}

\section{Oxytocin augmentation}

Oxytocin was started depending on the modified Bishops score and in absence of adequate uterine contractions after $6 \mathrm{hrs}$ of last dose, or for augmentation in case of arrest of dilation (Table 20). In the present study the requirement for oxytocin augmentation was more in the Dinoprostone group - $12 \%$ than in the Misoprostol group $-9.3 \%$, this was statistically insignificant. In this study need for oxytocin was very low when compared to all other studies in both the groups.

\section{Liquor}

The incidence of thick meconium stained liquor was $18.7 \%$ and $17.4 \%$ in Dinoprostone and Misoprostol groups respectively. More number of patients in the Dinoprostone group were induced for postdatism and found to have thick meconium stained liquor. It was not known whether the thick meconium was due to the drug or due to the indication for induction which was postdatism.

\section{Maternal side effects}

The maternal side effects observed were chills, tachysystole, hyperstimulation, vomiting, diarorhea, fever and $\mathrm{PPH}$. In the Dinoprostone group the major side effects were vomiting $-2.7 \%$ and $\mathrm{PPH}$ of which traumatic $-1.3 \%$ and $2.7 \%$ atonic. Vomiting was noticed in patients who had rapid dilation of the cervix and could have been a cause of the same. .

The major side effects observed in the Misoprostol group was chills $17.3 \%$, hyperstimulation $8 \%$, tachysystole $2.7 \%$, fever $2.6 \%$ and vomiting $2.7 \%$. Our observations are nearly consistent with the studies of Fletcher et al. ${ }^{7}$ and Wing et al. ${ }^{11}$ in regard to tachysystole and hyperstimulation respectively. The difference in the incidence of tachysystole and hyperstimulation by different authors could probably be attributed to the different dosing regimens. Misoprostol group had 1 patient with traumatic PPH and another one with atonic PPH. Both were treated promptly (Table 21 ).

\section{Neonatal outcome}

The mean birth weight and mean apgar scores in both groups did not show any major difference. The incidence of NICU admission was $10.6 \%$ in Dinoprostone group and 4.9\% in Misoprostol group. The 
indications for NICU admission were meconium aspiration syndrome, birth asphyxia, preterm care, respiratory distress syndrome, very low birth weight, low birth weight. There was an increased incidence of meconium aspiration syndrome in Dinoprostone group and birth asphyxia in the Misoprostol group. As discussed earlier, meconium stained liquor incidence was more in Dinoprostone group, hence the meconium aspiration syndrome incidence was more in Dinoprostone group. If we exclude this particular factor, incidence of NICU admissions in both the groups are almost equal.

Table 20 Oxytocin Augmentation

\begin{tabular}{|c|c|c|}
\hline Author and year & Dinoprostone [dosage (max dose)] & $\begin{array}{l}\text { Misoprostol } \\
\text { [dosage (max dose)] }\end{array}$ \\
\hline Wing DA et al." & $65.7 \%[0.5 \mathrm{mg} 3 \mathrm{hrs}(3)]$ & $33.8 \%[50 \mu \mathrm{g} 3 \mathrm{hrs}(6)]$ \\
\hline Herabutya et al. ${ }^{9}$ & $34 \%(1.5)$ & $35 \%(100 \mu g)$ \\
\hline Deborah et al. ${ }^{17}$ & - & $59.1 \%[25 \mu \mathrm{g} 4 \mathrm{hrs}(6)]$ \\
\hline Danelien et al. ${ }^{18}$ & $47 \%$ [I mg 6hrs(3)] & $21 \%[52 \mu \mathrm{g} 4 \mathrm{hrs}(4)]$ \\
\hline Present Study & $10.7 \%(0.5 \mathrm{mg} 6 \mathrm{hrs})(3)$ & $9.3 \% 50 \mu \mathrm{g} 6 \mathrm{hrs})(3)$ \\
\hline
\end{tabular}

Table 2 I Incidence of side effects with Misoprostol

\begin{tabular}{|c|c|c|c|}
\hline Author and year & Dosage & Tachysystole & Hyperstimulation \\
\hline Sanchez Ramos et al. ${ }^{10}$ & $50 \mu \mathrm{g} \mathrm{q} 4 \mathrm{hrs}$ & $34.40 \%$ & $10.90 \%$ \\
\hline Fletcher et al. $^{7}$ & $100 \mu \mathrm{g}$ single dose & $4.20 \%$ & $3.00 \%$ \\
\hline Wing et al." & $50 \mu \mathrm{g} \mathrm{q} 3 \mathrm{hrs}$ & $36.80 \%$ & $7.40 \%$ \\
\hline Wing et al. ${ }^{12}$ & $25 \mu \mathrm{g} \mathrm{q} 3 \mathrm{hrs}$ & $17.40 \%$ & $5.80 \%$ \\
\hline Bugalho et al..$^{8}$ & $25 \mu \mathrm{g} \mathrm{q} 3 \mathrm{hrs}$ & $14.60 \%$ & $5.80 \%$ \\
\hline Present Study & $50 \mu \mathrm{g} 6 \mathrm{hrs}$ & $2.70 \%$ & $8.00 \%$ \\
\hline
\end{tabular}

Mundle \& Young. ${ }^{19}$ evaluated the effect of Misoprostol for labour induction on neonatal outcome. They found that neonatal outcome was similar in both the groups (PGE1 and PGE2 groups), cord blood acid base analysis did not differ between both the groups. No neonate met the ACOG criteria for birth asphyxia in their study. Sanchez Ramos et al. ${ }^{20}$ their meta analysis found no differences in incidence of low 5 minutes apgar score and admission to NICU between Misoprostol and control groups. ${ }^{20}$

\section{Conclusion}

Misoprostol and Dinoprostone are safe and effective for cervical ripening and labour induction. Misoprostol is cost-effective when compared to Dinoprostone. Misoprostol is stable at room temperature and does not need refrigeration whereas Dinoprostone requires refrigeration. Induction to delivery time was shorter in misoprostol group when compared to dinoprostone group. One disadvantage with Misoprostol is uterine tachysystole and hyperstimulation with further fetal distress. Therefore further work is needed to determine the ideal dosing to prevent such complications. LSCS due to failure of induction was more in cerviprime group and LSCS due to fetal distress was more in misoprost group. NICU admissions in both the groups are almost equal in both the groups.

\section{Acknowledgments}

None.

\section{Conflicts of interest}

None.

\section{References}

1. Kudagi BL, Sailaja L, Pravin Kumar R,et al. A Comparative study of intravaginal misoprostol with intracervical dinoprostone gel for induction of labour in pregnancy. Asian J Pharma Clin Res. 2013;16(2):174-178.

2. Waraich S, Naqui Z. Comparision of intravaginal Misoprostol and Dinoprostone for Induction of Labour. Pakistan Journal of Surgery. 2009;25(3):209-213.
3. Truffater FK, Donette Bowers, Stanley AG, et al. Preinduction cervical ripening with PGE2 (Prepidil) gel. Am J Obstet Gynecol. 1985;153(3):268-271.

4. Macer J, Buchanan D, Yonekura ML. Induction of labor with prostaglandin E2 vaginal suppositories. Obstet Gynecol. 1984;63(5):664-668.

5. Nager CW, Key TC, Moore TR. Cervical ripening and labor outcome with preinduction intracervical prostaglandin E2 (Prepidil) gel. $J$ Perinatol. 1986;7(3):189-193.

6. Bernstein P, Leyland N, Gurland P, et al. Cervical repening and labor induction with prostaglandin E2 gel: A placebo-controlled study. Am J Obstet Gynecol. 1987;156(2):336-340.

7. Fletcher H, Mitchell S, Frederick J, et al. Intravaginal misoprostol versus dinoprostone as cervical ripening and labor-inducing agents. Obstet Gynecol. 199483(2):244-247.

8. Bugalho A, Bique C, Machungo F, et al. Low-dose vaginal misoprostol for induction of labor with a live fetus. Int $J$ Gynaecol Obstet. 1995;49(2):149-155.

9. Herabutya Y, O-Prasertsawat P, Pokpirom J. A comparison of intravaginal misoprostol and intracervical prostaglandin E2 gel for ripening of unfavorable cervix and labor induction. J Obstet Gynaecol Res. 1997;23(4):369-374.

10. Sanchez-Ramos L, Kaunitz AM, Del Valle GO, et al. Labor induction with the prostaglandin E1 methyl analogue misoprostol versus oxytocin: a randomized trial. Obstet Gynecol. 1993;81(3):332-336.

11. Wing DA, Jones MM, Rahall A, et al. A comparison of misoprostol and prostaglandin E2 gel for preinduction cervical ripening and labor induction. Am J Obstet Gynecol. 1995;172(6):1804-1810.

12. Wing DA, Rahall A, Jones MM, et al. Misoprostol: an effective agent for cervical ripening and labor induction. Am $J$ Obstet Gynecol. 1995;172(6):1811-1816.

13. Varaklis K, Gumina R, Stubblefield PG. Randomized controlled trial of vaginal misoprostol and intracervical prostaglandin E2 gel for induction of labor at term. Obstet Gynecol. 1995;86(4):541-544.

14. Özgür K, Kizilates A, Üner M, et al. Induction of labor with intravaginal misoprostol versus intracervical dinoprostone. Arch Gynecol Obstet. 1997;261(1):9-13. 
15. Blanchette HA, Nayak S, Erasmus S. Comparison of the safety and efficacy of intravaginal misoprostol (prostaglandin E1) with those of dinoprostone (prostaglandin E 2) for cervical ripening and induction of labor in a community hospital. Am J Obstet Gynecol. 1999;180(6):15511559 .

16. Kolderup L, McLean L, Grullon K, et al. Misoprostol is more efficacious for labor induction than prostaglandin E2, but is it associated with more risk? Am J Obstet Gynecol. 1999;180(6):1543-1550.

17. Wing DA, Ham D, Paul RH. A comparison of orally administered misoprostol with vaginally administered misoprostol for cervical ripening and labor induction. Am J Obstet Gynecol. 1999;180(5):11551160
18. Danielian P, Porter B, Ferri N, et al. Misoprostol for induction of labour at term: a more effective agent than dinoprostone vaginal gel. $\mathrm{Br} J$ Obstet Gynaecol. 1999;106(8):793-797.

19. Windrim R, Bennett K, Mundle W, et al. Oral administration of misoprostol for labor induction: a randomized controlled trial. Obstet Gynecol. 1997;89(3):392-397.

20. Sanchez-Ramos L, Peterson DE, Delke I, et al. Labor induction with prostaglandin E1 misoprostol compared with dinoprostone vaginal insert: a randomized trial. Obstet Gynecol. 1998;91(3):401-405. 